\title{
Recently Received Titles
}

If you are interested in reviewing one of the books listed here, please contact the editorial staff at ERbookreview@ aesop.rutgers.edu.

\section{The Guide to Greening Cities}

Sadhu Aufochs Johnston, Steven S. Nicholas and Julia Parzen (eds). 2013. Washington, D. C.: Island Press. $\$ 30.00$ Paperback. ISBN: 9781610913799. 264 pages.

\section{How to Study Public Life}

Jan Gehl and Birgitte Svarre. 2013. Washington, D.C.: Island Press. \$35.00 Hardcover. ISBN: 139781610914239. 200 pages.

\section{Tidal Wetlands Primer}

Ralph W. Tiner. 2013. Amherst, MA: University of Massachusetts Press. \$39.95 Paperback; \$98.00 Hardcover. ISBN: 9781625340290.536 pages.

\section{Ecovillages}

Karen T. Litfin. 2014. Cambridge, UK: Polity. \$19.99 Ebook; \$24.95 Paperback; \$69.95 Hardcover. ISBN: 9780745679495. 223 pages. 